\title{
PENGARUH QUALITY OF WORK LIFE TERHADAP WORK ENGAGEMENT PADA PEGAWAI NEGERI SIPIL (PNS) YANG BELUM MENIKAH
}

\author{
Nisa Indah Pertiwi*, Diana Harding, Nurul Yanuarti
}

${ }^{\star}$ Corresponding Author:

Fakultas Psikologi

Universitas Padjajaran

Email:

nisa14002@mail.unpad.ac.id diana.harding@unpad.ac.id nurul.yanuarti@unpad.ac.id

\begin{abstract}
Abstrak. Work engagement diketahui sebagai sumber bagi keberhasilan performa kerja individu dalam organisasi. Dalam hal ini, quality of work life menjadi salah satu topik yang menarik sebagai dasar dalam membentuk work engagement. Penelitian ini bertujuan untuk mengetahui pengaruh quality of work life terhadap work engagement pada Pegawai Negeri Sipil (PNS) yang belum menikah. Penelitian ini menggunakan metode kuantitatif non-eksperimental yang dilakukan kepada 63 orang PNS yang belum menikah. Alat ukur quality of work life menggunakan adaptasi kuesioner quality of work life dari Timossi dan work engagement menggunakan adaptasi alat ukur the Utrecht Work Engagement Scale (UWES-17). Teknik analisis data menggunakan uji regresi linier sederhana. Hasil penelitian menunjukkan bahwa quality of work life berpengaruh terhadap work engagement pada PNS yang belum menikah. Aspek development using human capacity memiliki kontribusi terbesar bagi quality of work life dalam mempengaruhi work engagement.
\end{abstract}

Kata Kunci: Quality of Work life, Work Engagement, Pegawai Negeri Sipil, belum Menikah

\begin{abstract}
Work engagement has been known as a source for the succes of individual work performance in the organization. In this case, quality of work life is an interesting topic as a basis for forming work engagement. This study aimed determine the effect of quality of work life on work engagement among unmarried Civil Servants (PNS). This study used non-experimental quantitative method which was conducted on 63 unmarried Civil Servants. Quality of work life instrument was adapted from quality of life questionnaire from Timossi and work engagement instrument was adapted from the Utrecht Work Engagement Scale (UWES-17). The data was analyzed through simple linear regression analysis. The results of this study showed the quality of work life has an effect on work engagement of unmarried Civil Servants. Development using human capacity has the greatest contribution to the quality of work life in effecting work engagement.
\end{abstract}

Keywords: quality of work life, work engagement, Civil Servant; unmarried

\section{PENDAHULUAN}

Sumber Daya Manusia merupakan faktor penting sebagai penggerak keberhasilan organisasi dalam mencapai tujuannya, baik yang bergerak pada sektor swasta maupun instansi pemerintahan negara. Instansi pemerintahan merupakan organisasi yang penting di dalam pemerintahan karena berkaitan dengan penyelenggaraan pemerintahan dan pembangunan negara (Winurini, 2010). Pekerja di dalam instansi pemerintahan disebut Pegawai Negeri Sipil (PNS) yang merupakan aparat negara dan abdi masyarakat. Dalam menjalankan pekerjaannya, PNS diharapkan mampu menyelenggarakan pelayanan secara adil dan merata sesuai dengan Pancasila dan Undang-Undang Dasar 1945. Untuk mencapai tujuan dari instansi pemerintahan, maka diperlukan PNS yang terikat pada 
pekerjaanya agar mereka mampu menyatu dengan pekerjaan dan mengeluarkan seluruh kemampuannya untuk menghasilkan performa kerja yang maksimal.

Keterikan pada pekerjaan disebut work engagement. Karyawan yang terikat (engaged) memiliki rasa energik dan hubungan yang efektif dengan kegiatan kerja serta melihat diri mereka mampu menangani tuntutan pekerjaan dengan baik (Schaufeli \& Bakker, 2004). Schaufeli \& Bakker (2004) mendefinisikan work engagement sebagai keadaan pikiran yang positif, memuaskan, dan berhubungan dengan pekerjaan yang memiliki karakteristik vigor, dedication, dan $a b$ sorption. Vigor merupakan curahan energi dan mental yang kuat selama bekerja, keberanian untuk berusaha sekuat tenaga dalam menyelesaikan pekerjaan, serta tekun dalam menghadapi kesulitan kerja. Dedication berkaitan dengan pegawai merasa keterlibatan yang kuat dalam suatu pekerjaan dan mengalami rasa kebermaknaan, antusiasme, kebanggaan, inspirasi dan tantangan. Absorption yaitu dalam bekerja pegawai selalu penuh konsentrasi dan serius terhadap suatu pekerjaan, dalam bekerja waktu terasa berlalu begitu cepat serta menemukan kesulitan dalam memisahkan diri dengan pekerjaan.

Work engagement berhubungan secara positif dengan kinerja atau job performance (Bakker \& Demerouti, 2008). Pegawai yang terikat pada pekerjaan akan bertanggung jawab, memiliki semangat, fokus pada pekerjaan, memiliki standar performa yang tinggi, dan berdidikasi. Hal ini akan mengarahkan pada penampilan kinerja yang dihasilkan. Kinerja yang optimal akan dihasilkan oleh pegawai yang memiliki keterikan yang tinggi pada pekerjaannya karena performa kerja merupakan indikator penting dari work engagement pegawai. Menurut Demerouti \& Cropanzano (2010) work engagement menangkap dua hal yaitu pekerja "can do" dan "will do", hal itu akan cenderung memiliki efek lebih kuat pada kinerja yang dihasilkan. Penelitian Soetrisno \& Sutanto (2017) menemukan bahwa work engagement memiliki pengaruh positif dan signifikan terhadap kinerja, artinya semakin tinggi work engagement karyawan maka kinerja karyawan juga semakin tinggi.

Terdapat tiga faktor pendorong work engagement yang dikenal dengan model Job Demands-Resources (JD-R) yaitu job resources, personal resources, dan job demands (Bakker et al., 2004; Bakker \& Demerouti, 2008; Xanthopoulou et al., 2007). Job resources mengacu pada aspek fisik, sosial, atau organisasi dari suatu pekerjaan yang dapat mengurangi tuntutan pekerjaan yang juga berhubungan dengan dampak fisik dan psikologis; berfungsi dalam pencapaian tujuan pekerjaan; serta menstimulasi personal growth, learning, dan development. Personal resouces adalah evaluasi diri yang positif terkait dengan ketahanan atau resiliensi dan memunculkan perasaan individu bahwa ia mampu mengontrol dan memberikan dampak pada keberhasilan lingkungan. Job demands merujuk pada aspek psikologis, sosial, atau organisasi dari pekerjaan yang membutuhkan upaya fisik dan/atau psikologis (kognitif dan emosional) yang berkelanjutan dan oleh karena itu terkait dengan dampak fisiologis dan/atau psikologis tertentu. Ketiga faktor pendorong work engagement ini dapat saling berinteraksi. Job demands yang tinggi dapat menguras resources pekerja dan dapat menghalangi penggunaan job resources. Job resources dan personal resources memiliki dampak positif pada work engagement ketika job demands tinggi (Bakker \& Demerouti, 2008). Maka, penting adanya faktor job resources dan personal resources untuk dapat menghadapi tuntutan pekerjaan ( job demands). Kombinasi antara job resources dan personal resources terdapat pada kualitas kehidupan kerja (quality of work life) yang ada pada pekerjaan.

Quality of work life (QWL) merupakan persepsi pekerja menganai kualitas hidup pekerja di tempat kerja kerja (Fernandes et al., 2017; Walton, 1975). QWL yang tinggi penting bagi organisasi karena menunjukkan organisasi dapat menawarkan lingkungan kerja yang sesuai kepada pekerja (Noor \& Abdullah, 2012). Gokhale (2015) menyimpulkan setelah meninjau berbagai literatur bahwa QWL lebih luas dari pada kepuasan kerja atau faktor intrinsik yang terkait dengan pekerjaan. Seiring dengan kepuasan kerja, beberapa konsep QWL juga memasukkan general well-being, workhome interaction, stres yang dialami di tempat kerja, lingkungan fisik, dan tingkat kontrol pada pekerjaan. Kanten \& Sadullah (2012) mengatakan bahwa QWL terkait dengan kesejahteraan pekerja di tempat kerja dan sangat berbeda dari kepuasan kerja, domain QWL tidak hanya mempengaruhi kepuasan kerja tetapi juga mempengaruhi kehidupan di luar pekerjaan seperti keluarga, leisure, dan kebutuhan sosial. QWL adalah kondisi kehidupan yang lebih baik atau kepuasan ekonomi, sosial, dan spiritual, yang dapat diukur dengan mengaplikasikan 8 dimensi dari quality of work life yaitu: adequate and fair compensation, safe and healthy working conditions, development using human capacity, growth and security, social integration, constitutionalism, work and total life space dan social relevance of work life (Walton, 1975).

Dalam hal ini, aspek QWL yang mencakup job resources yaitu adequate and fair compensation, safe and healthy working conditions, development using human capacity, growth and security, social integration dan constitutionalism. Sementara itu, aspek-aspek QWL 
yang mencakup personal resources yaitu work and total life space dan social relevance of work life.

Adequate and fair compensation diartikan sebagai pembayaran yang diberikan kepada pegawai dalam rangka memenuhi kehidupannya berdasarkan standar sosial secara umum. Safe and healthy working conditions terkait dengan kesehatan lingkungan kerja yang mencakup kondisi fisik dan jam kerja serta situasi kerja yang dapat mengurangi risiko kecelakaan dan permasalahan kesehatan. Development using human capacity berkaitan dengan pentingnya mengembangkan kapasitas pegawai serta kesempatan bagi pegawai untuk menggunakan dan mengembangkan pengetahuan dan kemampuan. Growth and security berkaitan dengan kesempatan yang diberikan kepada pegawai untuk mengembangkan kemampuan diri, peluang kenaikan pada pekerjaan serta kemungkinan untuk menggunakan pengetahuan dan keterampilan baru. Social integration berkaitan dengan aspek hubungan personal, rasa kebersamaan, kesetaraan sosial dan tidak ada diskriminasi atau perbedaan di tempat kerja. Constitutionalism diartikan sebagai hak yang dimiliki pegawai dan bagaimana mereka mendapatkannya, apakah organisasi menghormati hak pegawai dan perbedaan opini pada setiap pegawai, kebebasan berekspresi, serta keadilan dan kesetaraan di depan hukum. Work and total life space berkaitan dengan keseimbangan antara pekerjaan dan peran kehidupan pegawai lainya sehingga pegawai dapat lebih menikmati kehidupan personalnya. dan Social relevance of work life berkaitan dengan ketika organisasi mencari perbaikan dalam aspek-aspek seperti tanggung jawab sosial, serta persepsi karyawan tentang pentingnya tugas yang ia jalankan sehingga karyawan merasakan kebanggaan, persepsi karyawan terhadap tanggung jawab organisasi kepada masyarakat, citra organisasi, dan kualitas produk/servis.

Keterikatan pada pekerjaan bergantung pada bagaimana persepsi pegawai terhadap setting pekerjaan, sifat pekerjaan itu sendiri, pengaruh pekerjaan terhadap aspek kehidupan lainnya, dan kualitas kehidupan kerja yang membuat sejahtera. Work engagement dapat digerakkan oleh faktor working life melalui kenyaman lingkungan kerja. QWL dapat menjadi solusi dalam mengembangkan work engagement karena terdiri dari berbagai variabel penting yang jika ditingkatkan dapat membantu untuk menumbuhkan work engagement pegawai (Alqarni, 2016). Berdasarkan berbagai penelitan ditemukan bahwa QWL berhubungan dengan work engagement, seperti penelitian dari Kanten \& Sadullah (2012) yang menemukan bahwa QWL memiliki dampak terhadap work engagement pada staf perusahaan marmer di Turki. Selan- jutnya penelitian Alqarni (2016) menemukan bahwa dua dimensi QWL (development of human capacities dan sociaL relevance) signifikan sebagai prediktor work engagement pada teaching faculty di salah satu universitas di Arab Saudi. Penelitian Sahni (2019) menemukan bahwa terdapat hubungan yang lemah antara QWL dan employee engagement pada karyawan industri telekomunikasi di Arab Saudi. Di Indonesia, penelitian Nugroho et al. (2018) menemukan bahwa QWL memiliki pengaruh yang signifikan terhadap employee engagement pada karyawan di salah satu perusahaan.

Penelusuran berbagai penelitian terdahulu menemukan bahwa penelitian QWL dan work engagement biasanya mencampurkan antara pekerja yang belum menikah dan pekerja yang sudah menikah. Austrom et al. (1988) menyatakan bahwa ada perbedaan yang signifikan antara pekerja lajang dan pekerja yang menikah dalam berbagai sikap dan perilaku kerja. Perbedaan antara pekerja lajang dan pekerja menikah berimplikasi pada kebutuhan pekerja yang perlu disediakan oleh organisasi misalnya paket tunjangan yang ditawarkan, fungsi sosial terkait pekerjaan, program manajemen dan sebagainya, karena biasanya berbagai jenis bantuan dan paket tunjangan tertuju pada keluarga yang menguntungkan bagi pekerja yang sudah menikah (Austrom et al., 1988). Penelitian yang dilakukan oleh Soetrisno \& Sutanto (2017) menemukan bahwa karyawan yang sudah menikah memiliki work engagement dan juga kinerja yang tinggi dibandingkan karyawan yang belum menikah. Dengan adanya hubungan yang kuat antara status pernikahan dan perilaku kerja, Austrom et al. (1988) menyarankan bahwa perlunya perhatian penelitian empiris yang berfokus pada pekerja yang lajang.

Sejauh penelusuran peneliti, sampai saat ini belum ada penelitian yang mengkaji hubungan antara QWL dan work engagement pada PNS yang belum menikah. Hal ini dipandang perlu sebagai upaya peningkatan kinerja PNS, yang merupakan sumber daya manusia dalam penyelenggaraan pemerintahan negara, yang juga berperan sebagai pelayan bagi masyarakat pada umumnya. Selain itu, penelitian ini dapat menggambarkan kondisi QWL dan work engagement yang mendekati kesesuaian dengan konteks subjek penelitian baik konteks pekerjaan maupun konteks sebagai pekerja yang belum menikah. Penelitian ini diharapkan dapat memberikan sumbangan ilmiah dalam memperkaya pengetahuan yang berkaitan dengan QWL dan work engagement, serta menguji dan menganalisa pengaruh QWL terhadap work engagement khususnya bagi PNS yang belum menikah. Penelitian ini juga diharapkan bermanfaat secara praktis 
sebagai bahan pertimbangan bagi pihak berwenang dalam mengelola sumber daya manusia PNS ataupun membuat rencana strategis untuk merancang kondisi kerja sehingga dapat meningkatkan performa kerja. Maka, tujuan dari penelitian ini adalah untuk melihat pengaruh QWL terhadap work engagement pada PNS yang belum menikah. Hipotesis pada penelitian ini adalah quality of work life berpengaruh terhadap work engagement pada PNS yang belum menikah.

\section{METODE}

Penelitian ini menggunakan pendekatan kuantitatif non-eksperimental (Christensen, 2007). Subjek penelitian adalah 63 orang Pegawai Negeri Sipil yang belum menikah. Subjek dijaring dengan cara memberitahukan informasi mengenai penelitian ini pada jejaring pertemanan dan kenalan peneliti melalui pesan WhatsApp dan WhatsApp Group. Informasi untuk menarik partsipan berupa penjelasan mengenai penelitian dan tautan untuk mengisi kuesioner. Calon partisipan yang bersedia langsung mengisi pernyataan kesediaan, data demografi, diikuti kuesioner QWL dan work engagement.

Penelitian ini terdiri dari dua variabel, yaitu quality of work life (QWL) dan work engagement. Untuk mengukur QWL, peneliti mengadaptasi ke dalam bahasa Indonesia alat ukur yang disusun oleh Timossi et al. (2008) berdasarkan adaptasi dan evaluasi model quality of work life Walton. Kuesioner QWL terdiri dari 27 item yang menilai delapan dimensi QWL yaitu adequate and fair compensation (3 item), safe and healthy working conditions (4 item), development using human capacity (4 item), growth and security (3 item), social integration (3 item), constitutionalism (4 item), work and total life space (2 item) dan social relevance (4 item). Kuesioner berupa skala likert dengan 5 pilihan jawaban yaitu: 1 - sangat tidak puas, 2 - tidak puas, 3 - netral, 4 - puas, 5 - sangat puas.

Alat ukur QWL versi bahasa Indonesia memperoleh nilai reliabilitas sebesar 0,963 . Validitas item didapatkan melalui nilai Corrected item total correlation berkisar antara 0,481 sampai 0,862. Cara perhitungan skor yaitu pilihan jawab sangat tidak puas diskor 1, tidak puas diskor 2, netral diskor 3, puas diskor 4, sangat puas diskor 5. Skor total QWL didapatkan dengan menjumlahkan semua nilai pilihan jawaban responden pada masing-masing item.

Untuk mengukur work engagement, peneliti menggunakan alat ukur the Utrecht Work Engagement Scale (UWES-17) (Schaufeli \& Bakker, 2004) yang peneliti adaptasi ke dalam bahasa Indonesia. Pada penelitian ini, kuesioner work engagament terdiri dari 16 item yang menilai tiga dimensi work engagement yaitu vigor (6 item), dedication (5 item), dan absorption (5 item). Kuesioner berupa skala likert dengan 6 pilihan jawaban yaitu: 1 - hampir tidak pernah, 2 - jarang, 3 - kadang - kadang, 4 - sering, 5 - sangat sering, 6 - selalu.

Alat ukur work engagement versi bahasa Indonesia memperoleh nilai reliabilitas sebesar 0,923. Dalam versi bahasa Indonesia, 1 item dari dimensi absorption dihilangkan karena tidak memenuhi persyaratan minimun validitas item. Validitas item setelah penghapusan item diperoleh Corrected item total correlation berkisar antara 0,402 sampai 0,824. Cara perhitungan skor yaitu pilihan jawab hampir tidak pernah diskor 1 , jarang diskor 2, kadang - kadang diskor 3, sering diskor 4, sangat sering diskor 5, selalu diskor 6. Skor total work engagement didapatkan dengan menjumlahkan semua nilai pilihan jawaban responden pada masing-masing item.

Untuk mempermudah memberikan gambaran umum kondisi QWL dan work engagement, maka dilakukan kategorisasi terhadap skor rata-rata hasil pengukuran kedua variabel. Pembagian kelas pada kategorisasi dibagi menjadi 4 kelas, yaitu: rendah, sedang, cukup, dan tinggi. Batasan kategorisasi dihitung berdasarkan skor ideal masing-masing alat ukur (lihat tabel 1).

Tabel 1. Kategorisasi Quality of Work Life dan Work Engagement

\begin{tabular}{lll}
\hline Kategori & Quality of Work Life & Work Engegement \\
\hline Rendah & $1,00-2,00$ & $1,00-2,25$ \\
Sedang & $2,01-3,00$ & $2,26-3,50$ \\
Cukup & $3,01-4,00$ & $3,51-4,75$ \\
Tinggi & $4,01-5,00$ & $4,76-6,00$ \\
\hline
\end{tabular}

Teknik analisis data yang digunakan untuk menguji hipotesis penelitian adalah uji regresi linier sederhana dengan taraf kepercayaan 95\% $(\alpha=0,05)$. Analisis dilakukan menggunakan program Statistical Package for the Social Sciences (SPSS) versi 25. Sebelum dilakukan uji regresi, terlebih dahulu dilakukan pengujian terhadap asumsi-asumsi analisis regresi. Langkah yang dilakukan yakni mentrasformasikan data berskala ordinal yang didapatkan dari pengisian kuesioner penelitian menjadi skala interval dengan cara dikonversi menggunakan metode MSI (Method Succesive Interval). Kemudian dilakukan uji asumsi regresi berikutnya yaitu uji normalitas, linearitas dan homoskedastisitas.

Uji normalitas dilakukan dengan uji Kolmogorov Smirnov. Sebuah data dikatakan berdistribusi normal jika nilai signifikant $>0,05$. Nilai signifikansi Kolmog- 
orov Smirnov pada data penelitian ini sebesar 0,20, dimana $0,20>0,05$. Hal ini menunjukkan bahwa data pada penelitian ini berdistribusi normal.

Uji linearitas dilakukan dengan melihat gambaran scatterplot persebaran data dari kedua variabel. Berdasarkan hasil gambaran scatterplot, persebaran data kedua variabel dapat ditarik garis diagonal. Hal ini menunjukkan bahwa hubungan antara QWL dan work engagement bersifat linear.

Pengujian homoskedastisitas dilakukan untuk memastikan bahwa varians atau error dari satu pengamatan harus konstan dengan varians atau error pada pengamatan lain. Pengujian ini dilakukan dengan melihat scatterplot standardized value dan standardized residual, dimana bentuk grafiknya harus menyebar dan tidak membentuk corong. Hasil gambaran scatterplot antara standardized value dan standardized residual menunjukkan grafik data menyebar dan tidak membentuk corong, sehingga asumsi varians residu harus konstan (homoskedastisitas) terpenuhi.

\section{HASIL DAN PEMBAHASAN \\ Hasil}

Tabel 2. Data Demografi Partisipan

\begin{tabular}{lll}
\hline \multicolumn{1}{c}{ Kategori } & Frekuensi $(\mathrm{N}=63)$ & Persentase \\
\hline Jenis Kelamin & & \\
Laki - laki & 28 & 44 \\
Perempuan & 35 & 56 \\
\hline Usia & \\
$\leq 20$ & 1 & 1,5 \\
$21-25$ & 51 & 81 \\
$26-30$ & 10 & 16 \\
$>30$ & 1 & 1,5 \\
\hline Golongan & & \\
II/a & 6 & 9,5 \\
II/b & 2 & 3 \\
II/c & 6 & 9,5 \\
III/a & 49 & 78 \\
\hline Pendidikan & & \\
SMA/Sederajat & 2 & 3 \\
Diploma & 9 & 14 \\
D4, S1 & 52 & 83 \\
\hline
\end{tabular}

Berdasarkan sebaran demografi pada tabel 2, mayoritas partisipan berjenis kelamin perempuan (56\%). Partisipan didominasi oleh PNS yang berusia 21 - 25 tahun yaitu sebanyak 81\%. Berdasarkan golongan, partisipan didominasi oleh PNS dengan golongan III/a yaitu sebanyak 78\%. Sedangkan berdasarkan pendidikan terakhir didominasi oleh lulusan D4, S1 sebanyak 83\%.
Hasil analisis data deskriptif yang menggambarkan kondisi quality of work life (QWL) dan work engagement partisipan dapat dilihat pada tabel 3 dan tabel 4. Berdasarkan tabel 3, mayoritas pegawai berada pada kondisi QWL yang tergolong kategori cukup (47\%). 32\% partisipan tergolong kategori QWL yang tinggi. Selanjutnya $16 \%$ partisipan berada pada kondisi QWL sedang dan 5\% lainnya berada pada kondisi QWL rendah. Secara umum pagawai cukup puas terhadap kualitas kehidupan kerja pada pekerjaannya.

Tabel 3. Kategorisasi Quality of Work Life dan Work Engagement

\begin{tabular}{|c|c|c|c|c|}
\hline \multirow[t]{2}{*}{ Kategori } & \multicolumn{2}{|c|}{ Quality of Work Life } & \multicolumn{2}{|c|}{ Work Engagement } \\
\hline & $\mathrm{n}$ & $\%$ & $\mathrm{n}$ & $\%$ \\
\hline Rendah & 3 & 5 & 0 & 0 \\
\hline Sedang & 10 & 16 & 10 & 16 \\
\hline Cukup & 30 & 47 & 34 & 54 \\
\hline Tinggi & 20 & 32 & 19 & 30 \\
\hline
\end{tabular}

Tabel 4. Skor Rata-rata Dimensi Quality of Work Life dan Work Engagement

\begin{tabular}{lll}
\hline Dimensi & M & Kategori \\
\hline Quality of work life & & \\
Adequate and fair compensation & 3,85 & Cukup \\
Safe and healthy working conditions & 3,48 & Cukup \\
Development using human capacity & 3,53 & Cukup \\
Growth and security & 3,40 & Cukup \\
Social integration & 3,68 & Cukup \\
Constitutionalism & 3,50 & Cukup \\
Work and total life space & 3,40 & Cukup \\
Social relevance & 3,85 & Cukup \\
\hline Work Engagement & & \\
Vigor & 4,37 & Cukup \\
Dedication & 4,52 & Cukup \\
Absorption & 4,24 & Cukup \\
\hline
\end{tabular}

Berdasarkan tabel 4, terlihat bahwa kedelapan dimensi QWL berada pada kategori cukup. Dimensi QWL dengan rata-rata skor tertinggi yaitu adequate and fair compensation dan social relevance. Selanjutnya skor rata-rata diikuti secara berturut-turut oleh dimensi social integration, development using human capacity, constitutionalism, dan safe and healthy working conditions. Nilai rata-rata terendah dari pengukuran QWL yaitu pada dimensi growth and security dan work and total life space.

Hasil pengukuran work engagement berdasarkan tabel 3, menunjukkan bahwa lebih dari setengah partisipan menunjukkan perilaku work engagement pada kategori cukup (54\%). 30\% memiliki work engagement 
yang tergolong tinggi dan 16\% lainnya menunjukkam work engagament pada tingkatan sedang. Tidak terdapat pegawai yang memiliki work engagement pada kategori rendah. Secara umum pegawai cukup terikat dengan pekerjaannya.

Pada tabel 4, dapat dilihat bahwa ketiga dimensi work engagament berada pada kategori cukup. Dimensi dengan rata-rata skor tertinggi yaitu dedication, yang diikuti oleh dimensi vigor. Dimensi absorption berada pada hasil rata-rata skor terendah pada pengukuran work engagement pegawai.

Tabel 5. Hasil Uji Regresi

\begin{tabular}{|c|c|c|c|c|}
\hline Dimensi & $\mathrm{R}$ & $\begin{array}{c}\text { R Square } \\
\text { (R2) }\end{array}$ & $\mathrm{P}$ & Keterangan \\
\hline $\begin{array}{l}\text { Quality of Work } \\
\text { Life * Work En- } \\
\text { gagement }\end{array}$ & 0,770 & 0,593 & $0,000^{*}$ & Signifikan \\
\hline $\begin{array}{l}\text { Adequate and } \\
\text { fair compensation } \\
* \text { Work Engage- } \\
\text { ment }\end{array}$ & 0,469 & 0,220 & $0,000^{*}$ & Signifikan \\
\hline $\begin{array}{l}\text { Safe and healthy } \\
\text { working condi- } \\
\text { tions * Work En- } \\
\text { gagement }\end{array}$ & 0,656 & 0,431 & $0,000^{*}$ & Signifikan \\
\hline $\begin{array}{l}\text { Development us- } \\
\text { ing human ca- } \\
\text { pacity }{ }^{*} \text { Work En- } \\
\text { gagement }\end{array}$ & 0,714 & 0,510 & $0,000^{*}$ & Signifikan \\
\hline $\begin{array}{l}\text { Growth and secu- } \\
\text { rity * Work En- } \\
\text { gagement }\end{array}$ & 0,617 & 0,380 & $0,000^{*}$ & Signifikan \\
\hline $\begin{array}{l}\text { Social integration } \\
\text { * Work Engage- } \\
\text { ment }\end{array}$ & 0,612 & 0,375 & $0,000^{*}$ & Signifikan \\
\hline $\begin{array}{l}\text { Constitutionalism } \\
\text { * Work Engage- } \\
\text { ment }\end{array}$ & 0,671 & 0,450 & $0,000^{*}$ & Signifikan \\
\hline $\begin{array}{l}\text { Work and total } \\
\text { life space }{ }^{*} \text { Work } \\
\text { Engagement }\end{array}$ & 0,592 & 0,351 & $0,000^{*}$ & Signifikan \\
\hline $\begin{array}{l}\text { Social relevance } \\
* \text { Work Engage- } \\
\text { ment }\end{array}$ & 0,660 & 0,436 & $0,000^{*}$ & Signifikan \\
\hline
\end{tabular}

Note: ${ }^{\star}=\mathrm{p}<0,05$

Berdasarkan analisis regresi, didapatkan hasil yang ditunjukkan oleh tabel 5. Hasil pengujian hipotesis menunjukkan bahwa $p$-value $(0,000)<\alpha(0,05)$, sehingga dapat disimpulkan bahwa quality of work life berpengaruh terhadap work engagement pada Pegawai Negeri Sipil (PNS) yang belum menikah. Hasil tersebut mengindikasikan bahwa kepuasan terhadap kualitas kehidupan kerja pada pekerjaan pegawai berkontribusi terhadap peningkatan work engagement yang ditampilkan dalam bekerja. Adapun besar kontribusi QWL terhadap work engagement pegawai yaitu sebesar 59\%. Sementara itu, sebesar $41 \%$ dari work engagement yang ditampilkan pegawai dipengaruhi oleh faktor atau variabel lain yang tidak diteliti pada penelitian ini.

Kontribusi masing-masing dimensi QWL terhadap work engagement dapat dilihat pada tabel 5 . Dimensi development using human capacity memiliki kontribusi terbesar bagi QWL dalam mempengaruhi work engagement pegawai dibandingkan tujuh dimensi lainnya, yaitu sebesar 51\%. Dimensi dengan kontribusi terbesar kedua yaitu constitutionalism dengan kontribusi sebesar 45\%. Kontribusi dimensi QWL selanjutnya berturut-turut yaitu dimensi social relevance $(43 \%)$ dan safe and healthy working conditions (43\%), dimensi growth and security (38\%), dimensi social integration (37\%), serta dimensi work and total life space (35\%). Dimensi adequate and fair compensation menjadi dimensi dengan kontribusi terkecil bagi QWL dalam mempengaruhi work engagement yaitu sebesar $22 \%$.

\section{Pembahasan}

Penelitian ini bertujuan untuk menguji pengaruh QWL terhadap work engagement pada PNS yang belum menikah. Keberhasilan organisasi dalam mencapai tujuan tergantung pada performa kerja individu yang ada di dalam organisasi. Performa kerja yang optimal akan dihasilkan oleh pegawai yang memiliki keterikatan kerja (work engagement) yang tinggi. Work engagement berkaitan dengan dua hal yaitu pekerja "can do" dan "will do", sehingga cenderung memiliki efek lebih kuat pada kinerja yang dihasilkan (Demerouti \& Cropanzano, 2010). Dengan adanya peran work engagement terhadap kinerja individu, maka penting juga untuk mengidentifikasi variabel yang berkontribusi terhadap work engagement. Salah satu variabel yang dinilai penting untuk diteliti adalah Quality of Work Life (QWL).

Berdasarkan pengujian hipotesis, ditemukan bahwa QWL berpengaruh terhadap work engagement pada PNS yang belum menikah. Artinya persepsi pegawai terhadap kepuasan pada QWL berperan untuk meningkatkan keterikatan (engaged) pegawai terhadap pekerjaan. QWL memiliki kontribusi yang cukup besar terhadap pembentukan perilaku work engagement pegawai, yaitu sebesar 59\%. Sedangkan $41 \%$ dari work engagement dipengaruhi oleh faktor dari variabel lain yang tidak diteliti pada penelitian ini.

Hasil penelitian ini mendukung pandangan mod- 
el Job Demands-Resources (JD-R) yang menyatakan bahwa work engagement didorong oleh tiga faktor yaitu job resources, personal resources, dan job demands (Bakker et al., 2004; Bakker \& Demerouti, 2008; Xanthopoulou et al., 2007). QWL yang merupakan kombinasi dari job resources dan personal resources, pada penelitian ini terbukti berpengaruh terhadap work engagement. Beberapa aspek QWL yaitu adequate and fair compensation, safe and healthy working conditions, development using human capacity, growth and security, social integration dan constitutionalism termasuk faktor pendorong work engagement berupa job resources. Sedangkan aspek work and total life space dan social relevance of work life termasuk faktor pendorong work engagement yang berupa personal resources.

Work engagement memiliki tiga dimensi yaitu vigor, dedication, dan absorption (Bakker \& Demerouti, 2008). Persepsi pegawai pada masing-masing aspek QWL dapat mempengaruhi vigor, dedication, dan $a b$ sorption pada diri pegawai. Pada aspek adequate and fair compensation, pegawai perlu memperoleh pembayaran yang dapat memenuhi kebutuhannya dan tidak memiliki perbedaan yang signifikan dibandingkan dengan fungsi yang sama di tempat lain (Fernandes et al., 2017). Jika organisasi tidak mampu menyediakan kebutuhan pegawai terkait materi, maka pegawai dapat merasa bahwa kebutuhannya kurang terpenuhi. Kebutuhan yang kurang terpenuhi ini dapat mendorong pegawai merasa kurang well-being dengan pekerjaannya. Ketika well-being rendah, invidu dapat kesulitan berkonsentrasi pada pekerjaannya dan mengurangi kinerja (Gokhale, 2015). Sebaliknya, well-being dapat mendorong pegawai untuk terlibat sepenuhnya dengan pekerjaan, mampu berkonsentrasi serta merasa bahagia dalam bekerja. Oleh sebab itu, kompensasi yang tepat dan adil melalui well-being yang dirasakan dapat mendorong absorption pegawai.

Pada aspek safe and healthy working conditions, kondisi fisik yang sehat dan keamanan merupakan persyaratan mendasar bagi pegawai untuk melaksanakan pekerjaannya. Jika pekerja mempersepsikan bahwa organisasi mampu memenuhi persyaratan tersebut, maka dapat menimbulkan kepuasan bagi pegawai karena menyediakan tempat kerja yang membuat individu merasa dapat bekerja dengan baik (Gokhale, 2015). Pegawaipun merasa dihargai dan merasa menjadi bagian penting dari organisasi. Hal ini dapat membuat mereka mengalami rasa bermakna dan tertantang untuk melaksanakan pekerjaan. Selain itu, rasa kepuasan dan rasa dihargai membuat pekerja larut dalam pekerjaannya, merasa bahagia dalam pekerjaan, dan merasa tidak ada lagi hal yang perlu dilakukan selain bekerja. Dengan demikian, rasa kep- uasan terhadap kondisi pekerjaan dan rasa dihargai oleh organisasi dapat mendorong pegawai memiliki perilaku dedication dan absorption.

Pada aspek development using human capacity, organisasi perlu menyediakan sarana untuk pegawai agar mereka mampu bekerja dan berkontribusi dengan maksimal untuk pencapaian tujuan organisasi. Jika organisasi mampu membuktikan bahwa setiap pegawai berkontribusi penting bagi organisasi dan pencapaian tujuannya, dapat meningkatkan self-esteem pegawai (Sahni, 2019). Self-esteem membuat pegawai merasakan kepuasan yang lebih besar dengan potensi dan keterampilan yang mereka miliki. Hal ini membuat mereka merasa keterlibatan dalam bekerja merupakan sesuatu yang bermakna. Mereka juga akan merasa tertantang dan antusias untuk terus menampilkan potensi dan keterampilan mereka dalam pekerjaan. Dengan demikian, menyediakan sarana untuk mengembangkan kapisitas pegawai dapat mendorong mereka menampilkan perilaku dedication. Selain dedication, development using human capacity juga dapat memunculkan vigor pada pegawai. Karakteristik development using human capacity seperti pentingnya atau signifikansi pekerjaan, otonomi, dan umpan balik pekerjaan merupakan anteseden dari vigor karena berhubung dengan organizational-based self-esteem (Leiter \& Bakker, 2010). Self-esteem tersebut akan mendorong pegawai untuk bersedia menginvestasikan energi dan upaya dalam bekerja. Mereka juga akan terdorong untuk tetap tekun dan bertahan ketika menghadapi kesulitan pekerjaan.

Pada aspek growth and security, pekerja yang memperoleh kesempatan mengembangkan kemampuan dan potensinya melalui pelatihan ataupun pendidikan serta adanya pengembangan karir, akan merasakan kesempatan tersebut berharga bagi mereka. Rasa keberhargaan tersebut akan menjadi stimulus bagi pegawai untuk memiliki semangat yang lebih tinggi, bekerja dengan penuh energi dan kemauan menginvestasikan upaya untuk pekerjaan. Rasa keberhargaan juga memugkinkan pegawai untuk total dan serius dalam pekerjaan. Hal tersebut mencerminkan bahwa kesempatan untuk terus tumbuh dan keamanan pada pekerjaan dapat membentuk vigor dan absorption pada pegawai.

Pada aspek social integration, pegawai yang mempersepsikan bahwa di tempat kerja memiliki hubungan sosial yang rukun, bebas dari diskriminasi, dan adanya kebersamaan dalam kelompok akan membuat individu merasa feels good atau menjadikan hal tersebut sebagai pengalaman yang menyenangkan. Jika individu tidak senang dalam pekerjaannya, maka mereka akan sulit berkonsentrasi, merasa waktu sangat 
lambat berlalu dan sulit untuk serius pada pekerjaannya. Dengan demikian, social integration dibutuhkan untuk manampilkan absorption pegawai.

Pada aspek constitutionalism, pegawai yang merasakan organisasi dapat melindungi hak dan menghormati mereka sebagai individu akan mempersepsikan bahwa organisasi memiliki kepedulian kepada pegawai. Pegawai dapat merasakan well-being karena organisasi peduli dan menghargai mereka. Ketika well-being rendah, invidu dapat kesulitan berkonsentrasi pada pekerjaannya dan mengurangi kinerja (Gokhale, 2015). Sebaliknya, well-being dapat menyebabkan pegawai untuk terlibat sepenuhnya dan merasa bahagia dalam pekerjaannya. Well-being yang dirasakan juga akan mendorong pegawai berani berusaha sekuat tenaga untuk menyelesaikan pekerjaan, tekun dan tetap bertahan dalam menghadapi kesulitan. Peraturan yang berlaku di tempat kerja melalui well-being yang dirasakan mendorong perilaku $a b$ sorption dan vigor pegawai.

Pada aspek work and total life space, organisasi perlu menyadari kebutuhan pegawai di luar pekerjaan dan menyeimbangkannya dengan tuntutan pekerjaan. Ketidakseimbangan pada pekerjaan dan kehidupan lainnya dapat menimbulkan konflik dan ketegangan dalam diri individu, bahkan burnout dan depresi (Gokhale, 2015). Ketegangan yang ada pada diri individu akan membuatnya kurang semangat dalam bekerja, tidak ada upaya dalam menyelesaikan pekerjaan, mudah lelah dan tidak kuat dalam menghadapi tantangan pekerjaan. Selain itu, pegawai menjadi tidak memiliki antusias dan tidak merasa tertantang dalam pekerjaan. Di sisi lain, pegawai juga akan sulit berkonsentrasi pada tugas dan tidak mampu terlibat sepenuhnya di dalam pekerjaan. Dengan demikian, aspek work and total life space diperlukan untuk menampilkan vigor, dedication, dan absorption pada pegawai.

Pada aspek social relevance of work, ketika organisasi mencari perbaikan pada aspek-aspek tanggung jawab sosial, maka cenderung dapat meningkatkan self-esteem pegawai (Fernandes et al., 2017). Self-esteem muncul dari rasa pencapaian karena pegawai dapat bekerja pada organisasi yang dinilai memiliki kontribusi besar terhadap masyarakat. Pegawai akan merasa bangga dan menilai bahwa pekerjaan adalah sesuatu yang bermakna. Pekerjaan yang bermakna dapat memberikan stimulus pribadi yang lebih besar dalam keterikatan pegawai (Sahni, 2019). Bahkan jika mereka merasa lelah, keterlibatan pada pekerjaan akan digambarkan sebagai keadaan yang menyenangan karena berhubungan dengan suatu pencapaian (Gokhale, 2015). Sehingga pegawai yang merasa bangga akan pencapaian organisasinya tidak mudah lelah dalam bekerja, mau menginvestasikan segala upaya untuk pekerjaan, dan berani menghadapi tantangan pekerjaan. Selain itu, pegawai juga merasa antusias, bangga, dan merasa pekerjaan adalah hal yang bermakna. Dengan demikian, aspek social relevance of work life diperlukan untuk menampilkan vigor dan dedication.

Berdasarkan hasil penelitian ini, mayoritas partisipan cukup puas terhadap kualitas kehidupan kerja (QWL) pada pekerjaannya. Artinya, mayoritas PNS yang menjadi partisipan penelitian ini merasa cukup puas terhadap ekonomi, sosial, dan spiritual serta cukup merasakan kebermaknaan pada kehidupan dan pekerjaannya. Persepsi pegawai terhadap QWL dapat mempengaruhi pembentukan work engagement yang ditampilkan. Pegawai yang mempersepsikan cukup puas terhadap kondisi QWL pekerjaan menjadi cenderung memiliki work engagement yang cukup tinggi pada pekerjaannya. Mayoritas PNS yang menjadi partisipan pada penelitian ini cukup terikat (engaged) pada pekerjaannya. Dalam menjalankan pekerjaan, mereka sudah memenuhi tuntutan in-role performances, namun belum ada kesediaan untuk melaksanakan extra-role performance. Artinya, pegawai sudah memenuhi tugas yang secara langsung mempengaruhi produktivitas kerja seperti tugas harian, namun belum melakukan aktivitas yang mendukung organisasi tapi tidak secara langsung mempengaruhi produktivitas seperti perilaku proaktif. Hal ini dikarenakan mereka belum sepenuhnya terikat kuat dengan pekerjaan sehingga belum ada kesediaan untuk bekerja ekstra dan proaktif dalam bekerja.

Mayoritas PNS yang menjadi partisipan penelitian ini merasa cukup puas terhadap QWL sejalan dengan hasil rata-rata semua dimensi QWL yang dinilai cukup memuaskan bagi pegawai. Meskipun semua dimensi tergolong cukup memuaskan, namun terdapat perbedaan nilai pada masing-masing dimensinya. Nilai rata-rata tertinggi yaitu pada dimensi adequate and fair compensation dan social relevance. Hal ini berarti, pegawai mempersepsikan bahwa kompensasi yang seimbang dan adil serta pemenuhan tanggung jawab instansi terhadap masyarakat, dinilai sebagai aspek yang paling menunjang kepuasannya terhadap QWL. Sedangkan nilai rata-rata terendah ada pada dimensi growth and security dan work and total life space. Dengan demikian, partisipan merasa cukup puas dengan kesempatan untuk terus tumbuh dan keamanan, namun pekerjaan sebagai PNS perlu memenuhi aturan-aturan yang sudah baku di dalam undang-undang berkaitan dengan pertumbuhan pada pekerjaan. Misalnya, kenaikan pangkat dan golongan 
yang sudah diatur menurut masa kerja dan penyesuaian ijazah serta kesempatan tugas belajar yang memiliki persyaratan cukup ketat. Dari sisi work and total life space, partisipan cukup puas dengan dampak pekerjaan terhadap keseluruhan kehidupan, namun jam kerja dan beban kerja tetap bisa mempengaruhi urusan keseharian di luar pekerjaan.

Mayoritas partisipan menunjukkan perilaku cukup terikat dengan pekerjaannya, sejalan dengan hasil rata-rata semua dimensi work engagement yang menujukkan partisipan cukup terikat. Meskipun semua dimensi berada pada kategori cukup, namun terdapat perbedaan pada nilai rata-rata dimensi-dimensinya. Nilai rata-rata tertinggi berada pada dimensi dedication. Hal ini berarti, pegawai merasa pekerjaannya bermakna, menantang, menginspirasi dan adanya perilaku antusias dalam bekerja, menjadi aspek yang paling menunjang work engagement mereka.

Hasil pengujian hipotesis menemukan bahwa QWL berpengaruh terhadap work engagement pada PNS yang belum menikah. Berdasarkan analisis kontribusi masing-masing dimensi QWL terhadap work engagement, ditemukan bahwa dimensi development using human capacity memiliki kontribusi terbesar bagi QWL dalam mempengaruhi work engagement yaitu sebesar 51\%. Hal ini menujukkan bahwa aspek QWL yang paling berperan bagi PNS yang belum menikah dalam membentuk perilaku work engagement adalah kesempatan untuk mengembangkan kapasitas diri meliputi otonomi yang diberikan kepada pegawai, tingkat kepentingan tugas yang dikerjakan, evaluasi kinerja, dan tanggung jawab pekerjaan yang diberikan. PNS yang belum menikah pada umumnya berada pada usia muda yang cenderung memiliki keinginan untuk meng-explore berbagai hal dalam pekerjaan. Oleh sebab itu, hal yang paling mereka butuhkan dari pekerjaan diantaranya otomoni dalam membuat keputusan atau menentukan cara kerja, kesempatan mengerjakan tugas yang memiliki dampak signifikan terhadap organisasi, umpan balik kinerja agar mereka dapat terus belajar dan memperbaiki kinerja, serta tanggung jawab yang diberikan kepada mereka. Ketika hal tersebut terpenuhi, PNS yang pada umumnya masih diusia muda ini akan merasakan bahwa ia memiliki kontribusi penting bagi instansi. Jika organisasi mampu membuktikan bahwa setiap pegawai berkontribusi penting bagi organisasi dan pencapaian tujuannya, maka dapat meningkatkan self-esteem pekerja (Sahni, 2019). Hal inilah yang dapat mendorong pegawai terikat (engaged) pada pekerjaannya. Di sisi lain, kontribusi terkecil bagi QWL dalam mempengaruhi work engagement ada pada di- mensi adequate and fair compensation yaitu sebesar $22 \%$. Aspek kompensasi menjadi faktor terakhir yang dapat meningkatkan work engagement bagi PNS yang belum menikah.

Hasil penelitian ini menemukan keunikan pada subjek PNS yang belum menikah, bahwa bukan kompensasi yang membuat mereka terikat dengan pekerjaan, namun kesempatan yang diberikan agar mereka dapat memberikan kontribusi yang signifikan bagi instansi tempat mereka bekerja. Nampaknya, dengan memberikan kesempatan untuk berkontribusi dalam mencapai kesuksesan instansi dalam melayan masyarakat, menjadi hal yang bermakna yang dapat mendorong mereka "will do" dan "can do" dalam bekerja. Kesempatan untuk ikut andil secara signifikan dalam mencapai tujuan instansi jauh lebih dapat membentuk work engagement PNS yang belum menikah dibandingkan gaji dan kompensasi materi.

Penelitian ini menemukan bahwa quality of work life berpengaruh terhadap work engagement pada PNS yang belum menikah. Hasil penelitian ini mendukung pandangan model Job Demands-Resources (JD-R) (Bakker et al., 2004; Bakker \& Demerouti, 2008; Xanthopoulou et al., 2007), dimana QWL yang merupakan kombinasi dari faktor job resources dan personal resources terbukti berperan dalam membentuk work engagement. Temuan penelitian ini sesuai dengan hasil penelitian sebelumnya, antara lain penelitian dari Kanten \& Sadullah (2012) yang menemukan bahwa QWL memiliki dampak terhadap work engagement pada staf perusahaan marmer di Turki, penelitian Sahni (2019) menemukan bahwa terdapat hubungan yang lemah antara QWL dan employee engagement pada karyawan industri telekomunikasi di Arab Saudi, serta penelitian Nugroho et al. (2018) menemukan bahwa QWL memiliki pengaruh yang signifikan terhadap employee engagement pada karyawan salah satu perusahaan di Indonesia.

Penelitian ini menemukan bahwa dimensi development using human capacity memiliki kontribusi terbesar bagi QWL dalam mempengaruhi work engagement. Hal ini merupakan keunikan dari subjek penelitian yaitu PNS yang belum menikah, dimana bukan gaji atau kompensasi materi yang berkontribusi besar terhadap keterikatan kerja mereka, namun kesempatan untuk dapat memberikan kontribusi signifikan bagi kesuksesan instansi tempat bekerja. Temuan ini sejalan dengan hasil penelitian Alqarni (2016) bahwa development using human capacity signifikan sebagai prediktor work engagement pada teaching faculty di salah satu universitas di Arab Saudi. Implikasi dari temuan ini yaitu untuk meningkatkan work engagement PNS yang belum menikah, intervensi dasar 
dapat dilakukan dengan sasaran untuk memastikan bahwa pegawai merasa puas pada aspek development using human capacity. Hal ini dikarenakan ketika pegawai memiliki kesempatan untuk menunjukkan potensi mereka dengan peluang untuk pengembangan personal, akan mendorong mereka untuk menyesuaikan dengan pekerjaan dan lebih kecil kemungkinan mangkir dari tugas (Alqarni, 2016).

\section{KESIMPULAN DAN SARAN}

\section{Kesimpulan}

Berdasarkan hasil penelitian, ditemukan bahwa quality of work life berpengaruh terhadap work engagement pada PNS yang belum menikah. Mayoritas PNS yang menjadi partisipan pada penelitian ini mempersepsikan bahwa mereka merasa cukup puas terhadap ekonomi, sosial, dan spiritual serta cukup merasakan kebermaknaan pada kehidupan dan pekerjaannya. Selain itu, mayoritas partisipan cukup terikat (engaged) pada pekerjaannya. Aspek development using human capacity memiliki kontribusi terbesar bagi QWL dalam mempengaruhi work engagement pada PNS yang belum menikah.

\section{Saran}

Terdapat beberapa saran bagi peneliti selanjutnya yang mengkaji topik penilitian ini. Pertama, mengingat kontribusi QWL terhadap work engagement sebesar 59\%, sehingga diharapkan ada penelitian yang mengidentifikasi faktor-faktor lain yang berpengaruh terhadap work engagement terutama dari segi job demand. Kedua, peneliti selanjutnya diharapkan melakukan perbandingan QWL antara pekerja yang sudah menikah dengan pekerja yang belum menikah, agar didapatkan pengetahuan yang lebih komprehensif sebagai pijakan awal dalam merancang kondisi kerja yang sesuai dengan kebutuhan pekerja.

\section{DAFTAR PUSTAKA}

Alqarni, S. A. Y. (2016). Quality of Work Life as a Predictor of Work Engagement among the Teaching Faculty at King Abdulaziz University. International Journal of Humanities and Social Science, 6(8), 118-135. www.ijhssnet.com

Austrom, D. R., Baldwin, T. T., \& Macy, G. J. (1988). The Single Worker: an Empirical Exploration of Attitudes, Behavior, and Well-Being. Canadian Journal of Administrative Sciences, 5(4), 22-29. https://doi.org/10.1111/j.1936-4490.1988. tb00491.x

Bakker, A. B., \& Demerouti, E. (2008). Towards a Model of Work Engagement. Career Development International, 13(3), 209-223. https://doi. org/10.1108/13620430810870476

Bakker, A. B., Demerouti, E., \& Verbeke, W. (2004). Using the Job Demands-Resources Model to Predict Burnout and Performance. Human Resource Management, 43(1), 83-104. https:/doi. org/10.1002/hrm.20004

Christensen, L. B. (2007). Experimental Methodology 10th ed. Pearson Education Inc.

Demerouti, E., \& Cropanzano, R. (2010). From Thought to Action: Employee Work Engagement and Job Performance. In Work Engegement: A Handbook of Essential Theory and Research (pp. 147-163). Psychology Press Taylor \& Francis Group.

Fernandes, R. B., Martins, B. S., Caixeta, R. P., Da Costa Filho, C. G., Braga, G. A., \& Antonialli, L. M. (2017). Quality of work life: An evaluation of Walton model with analysis of structural equations. Espacios, 38(3), 5.

Gokhale, M. (2015). Work-Related Quality of Life and Work Engagement.

Kanten, S., \& Sadullah, O. (2012). An Empirical Research on Relationship Quality of Work Life and Work Engagement. Procedia - Social and Behavioral Sciences, 62, 360-366. https://doi. org/10.1016/j.sbspro.2012.09.057

Leiter, M. P., \& Bakker, A. B. (2010). Work Engagement: Introduction. In Work Engagement: A Handbook of Essential Theory and Research (pp. 1-9). Psychology Press Taylor \& Francis Group.

Noor, S. M., \& Abdullah, M. A. (2012). Quality Work Life among Factory Workers in Malaysia. Procedia - Social and Behavioral Sciences, 35, 739-745. https://doi.org/10.1016/j.sbspro.2012.02.144

Nugroho, A. R., Budi, W., \& Susanto, B. (2018). Pengaruh Quality of Work Life dan Gaya Kepemimpinan Transformasional terhadap Employee Engagement pada Karyawan CV. X Cabang Kabupaten Tulungagung dan Blitar. Jurnal Psikologi Poseidon (Jurnal Ilmiah Psikologi Dan Psikologi Kemaritiman), 1(1), 1-13. https://doi.org/10.30649/ jpp.v1i1.9

Sahni, J. (2019). Role of Quality of Work Life in determining Employee Engagement and Organizational Commitment in Telecom Industry. International Journal for Quality Research, 13(2), 285-300. https://doi.org/10. 24874/IJQR13.02-03 Schaufeli, W., \& Bakker, A. (2004). Utrecht Work Engagement Scale: Preliminary Manual. Occupational Health Psychology Unit Utrecht University.

Soetrisno, L. C. P., \& Sutanto, E. M. (2017). Pengaruh Keterikatan Kerja dan Persepsi Dukungan Organisasional terhadap Kinerja Karyawan PT . Sukses 
Mekar Abadi. AGORA, 5(3).

Timossi, L. da S., Pedroso, B., Francisco, A. C. de, \& Pilatti, L. A. (2008). Evaluation of Quality of Work Life: an Adaptation From the Walton'S Qwl Model Xiv International Conference on Industrial Engineering and Operations Management. XIV INTERNATIONAL CONFERENCE ON INDUSTRIAL ENGINEERING AND OPERATIONS MANAGEMENT.

Walton, R. E. (1975). Criteria for Quality of Work Life. In Quality of Working Life: Problems, Projects and the State of the Art (pp. 91-104). Free Press.

Winurini, S. (2010). Quality of Working Life (QWL) Pegawai Negeri Sipil (PNS) di Sekretariat Jenderal DPR RI. Aspirasi, 1(2), 281-306.

Xanthopoulou, D., Bakker, A. B., Demerouti, E., \& Schaufeli, W. B. (2007). The Role of Personal Resources in the Job Demands-Resources Model. International Journal of Stress Management, 14(2), 121-141. https://doi.org/10.1037/10725245.14.2.121 